\author{
Przemysław Toczek*, Rafał Wiśniowski*, Stanisław Stryczek*, \\ Jan Ziaja*, Chrystian Mazur**
}

\title{
TOTAL SPECIFIC ENERGY (TSE) AS A NEW INDICATOR OF DRILLING EFFICIENCY
}

\section{INTRODUCTION}

Development of a borehole is a very complex and multi-parameter technological process. The proper execution of such a drilling endeavor, namely an exploratory borehole, is affected by a number of factors, many of which depend on the engineers who oversee the course of the whole process. During drilling a borehole, the drill bit (e.g. a cone, a polycrystalline diamond compact or a diamond bit) must meet the requirements of the nominal meters per day guaranteed by the manufacturer. Often it is difficult, given the type of rock layers that are drilled, which to a lesser or greater extent (depending on their physicomechanical properties) cause wear of the drill bit used in the drill string at a given moment. The wear of the tools also stems from the axial thrust put on the bit and its revolutions as well as hydraulic parameters and properties of the drilling mud. The aforementioned parameters are external. Their values are influenced by the geological formation which is being drilled through at the time and complications which often occur during drilling works [4].

Every borehole has its distinctive lithology, which varies in successive layers of drilled rocks in every region and every area where drilling works are conducted. These differences are mostly in the form of varying depths of layers, their character and physicomechanical properties (density, porosity, water absorption, hardness, abrasion resistance, drillability, compressive strength, flexural strength, shear strength). The influence of the aforementioned factors should be the result of a comprehensive analysis of information from previous drilling works conducted in a given region [3].

For a drilling process to progress properly, one needs to carefully analyze the geological-and-technical project of the borehole. It is important to be able to select optimal parameters in the initial phase of designing the drilling technology and selection of tools required

* AGH University of Science and Technology, Faculty of Drilling Oil and Gas, Krakow, Poland

** AGH University of Science and Technology, Faculty of Drilling Oil and Gas, Krakow, Poland - PhD student 
to carry out the task. The values aid in the achievement of maximum drilling effect, whose measurement can be maximum drilling rate [3], minimum cost of drilling one running meter or other optimization criteria.

Data from drilling exploratory boreholes for unconventional gas was used in the description of the way mechanical specific energy (MSE), total specific energy (TSE), reacts. The works were carried out in the Precambrian platform (Fig. 1), built mainly of two structural levels. The lower one, which is a crystalline foundation residing at different depths (240-6000 m below the surface), and the upper one, generally containing sedimentary rocks, unevenly distributed on a crystalline foundation.

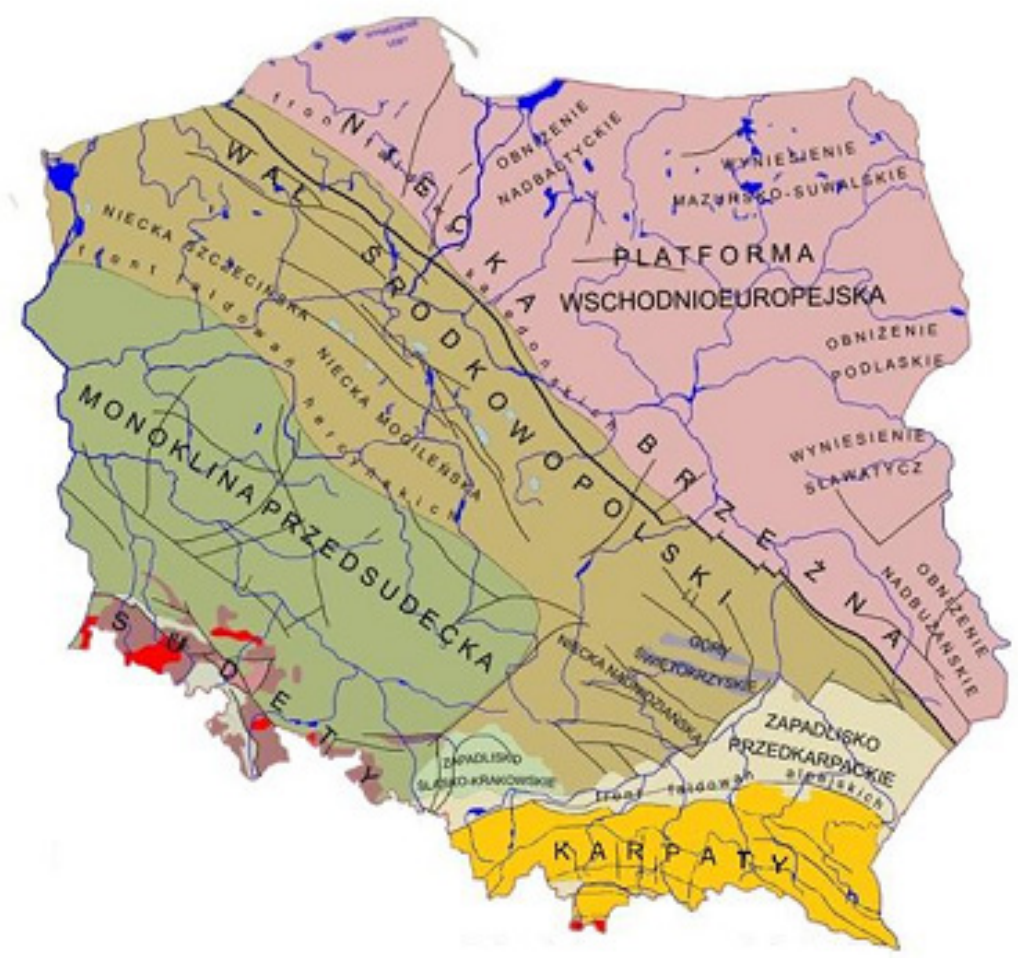

Fig. 1. Units of the geological structure of Poland

The drill bits which were analyzed were described in the article using the IADC (International Association of Drilling Contractors) code. IADC classification is used in the oil industry around the world. Thus, it was possible to standardize the selection of drill bits for future drilling works based on previous ones. It gives the basis for comparison and analysis of parameters resulting from application of particular drill bits, which are endangered by various geological and technical factors during drilling. One of main factors influencing the operation of drill bits during drilling a borehole are the type of layers it has to drill through [4]. 


\section{SELECTION OF DRILL BITS FOR ROTARY DRILLING}

The noticeable technological development of drill bits and measurement systems for rotary drilling has changed the attitude of engineers towards the topic of prediction and selection of drill bits for drilled rock layers. Evaluation of their efficiency and preliminary selection of drill bits greatly influences the drilling program of a new borehole [1] Evaluation of drill bits is an important factor both economically and technologically.

As the technology of drilling tools production has developed, new selection methods arose, depending on the type of drilled layers of the rock mass. The aim of these methods was to optimize technological and economical prediction of drilling tools.

\section{Drilling unit cost}

The most known and often applied method of identification and selection of drill bits is the unit cost criterion. It is a mathematical calculation of the cost of drilling one running meter of a borehole. It includes parameters such as cost of a drill bit in operation, drilling rate, time for operations accompanying borehole drilling (inserting, lifting drill string elements, exchange of the BHA, tightness tests of BOP's and others) and the distance drilled with the bit. Evaluation of efficiency of a drill bit based on the unit cost is often used in practice. However, it should be emphasized that it is an evaluation which is calculated based on economic aspects of the drilling process [1].

The bit for drilling in a rock mass interval was selected based on the experience of engineers who had previously participated in drilling works in the same borehole fields [5]. Rarely did the drill selection fit a given case. Currently, selection of a drill for a particular rock mass interval is the result of a complex analysis of collected data. It is mostly based on geophysical profiles of existing boreholes in a given region. Additionally, the basic operational parameters of a drill that were recorded during drilling (such as axial pressure on the bit, rotary speed of the drill bit, hydraulic parameters and parameters of the drilling fluid as well as work duration) are also taken into account. Drill bit selection criteria (parameters of the running drilling tool, drilling unit cost) result from analysis of data from boreholes previously drilled in a given area. The analysis of archive data of drill bits previously used in a given geological region (drilling rate, unit cost) does not reflect conditions which will be faced while drilling a new borehole, mostly because of the geology and stratigraphy of rocks. The operation of drilling tools is largely influenced by tectonic traps, faults and dips.

The drilling unit cost can be simply presented in the following formula:

$$
K_{m}=\frac{K_{d b}+(T+t) \cdot K_{d r}}{H}
$$

where:

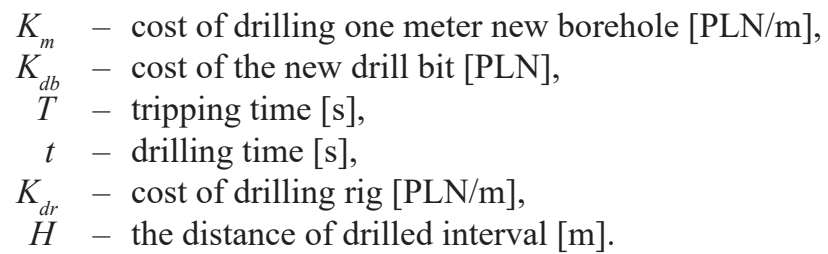

Note: All units related costs You can prepare, in Your own foreign exchange 
The application of the equation as a criterion of drill bit selection, regardless of visible and comparable parameters, depends on five parameters which influence the final result significantly. Moreover, time for inserting and lifting the drilling tool is not always easy to determine. Operations such as the wiper trip is not accounted for.

The final result of equation (1) is greatly influenced by the cost of drilling. If we consider the same drilled interval and drilling speed in it with different kinds of drill bits, having different $K_{d r}$, we conclude that using the same bit will generate a different unit drilling cost per one running meter of a borehole .

Taking this into consideration, we have to emphasize that criteria of drill bit selection should aim at the minimization of $K_{m}$ from equation (1). The cost of one running meter of a new borehole is calculated so as to facilitate the determination of the efficiency of a given drill bit. The total cost of drilling one running meter is calculated. It is widely assumed that if the total drilling cost rises, the drill bit should be exchanged with a new one or a bit complying with technical and technological requirements of a given borehole.

\section{Mechanic Specific Energy, MSE}

In 1986, H. Rabia together with M. Farelly, working at the University of Newcastle upon Tyne, applied a method of drill bit selection based on the so called specific energy.

The concept had already been described by, among others, R. Teale in 1965 [2]. He described specific energy as an index of mechanical efficiency describing processes related to crushing, drilling or any other breach of balance in any part of a rock mass, which it refers to.

The process of breaking and crushing rocks on the bottom of a borehole during drilling, in much simplification, depends on WOB and torque, resulting from rotation of the kelly or the top drive. In the case of mud motors, the revolutions of the drilling tool and torque originates in the rotation of the motor.

MSE was defined as the energy required to comprise a volumetric unit of the rock. The amount or the value of energy necessary depends on orogeny and its conditions influencing the creation of the drilled rock.

$$
M S E=\frac{4 W \cdot R+8 \pi \cdot N \cdot T}{D^{2} \cdot R}
$$

where:

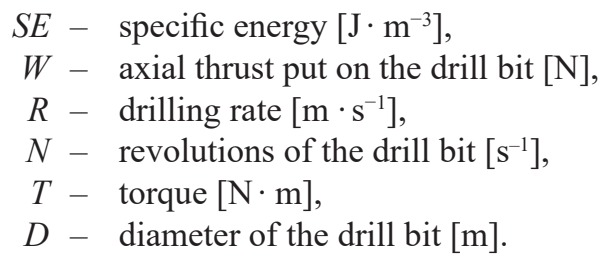

An alternative for specific energy presented by Teale is the equation presented by H. Rabia He presented an equation for specific energy which does not require the knowledge of torque. According to H. Rabia, mechanic specific energy can be described with the following equation (symbols are the same as in equation (2)). 


$$
M S E=\frac{4 W \cdot N}{R}
$$

In order to compare the aforementioned equations, complex drilling reports from the undergoing drilling works must be in possession. First and foremost, they must contain data required to solve MSE equations.

A comparison of MSE values according to Teale and Rabia is provided below (Fig. 2a-d). The curves depict the behavior of MSE while drilling a borehole with $8 \frac{1}{2}$ " and $12 \frac{1}{4}$ " drill bits. The works have been conducted in northern Poland, in the Peri-Baltic Syneclise, which is a part of the Precambrian platform.

a)

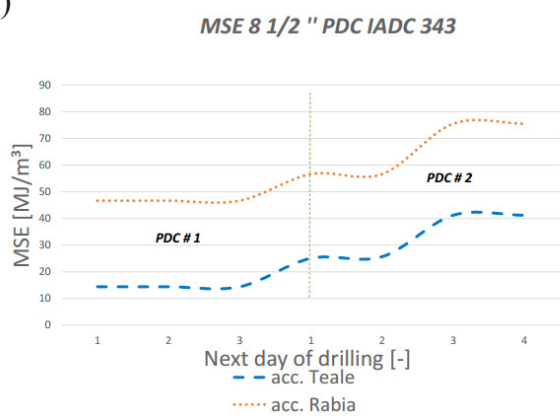

c)

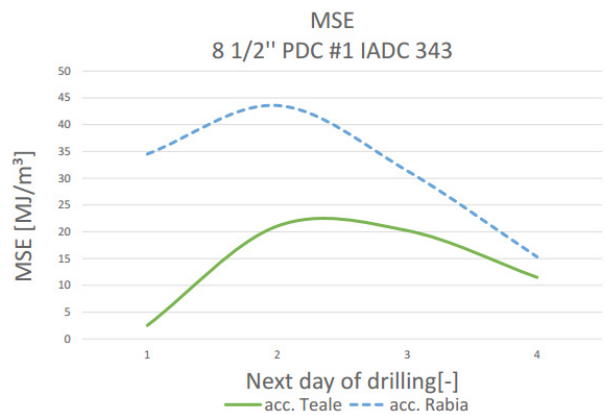

b)

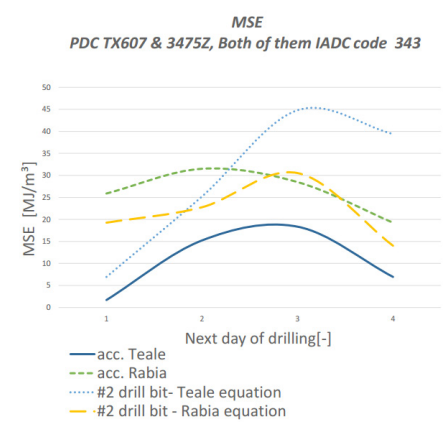

d)

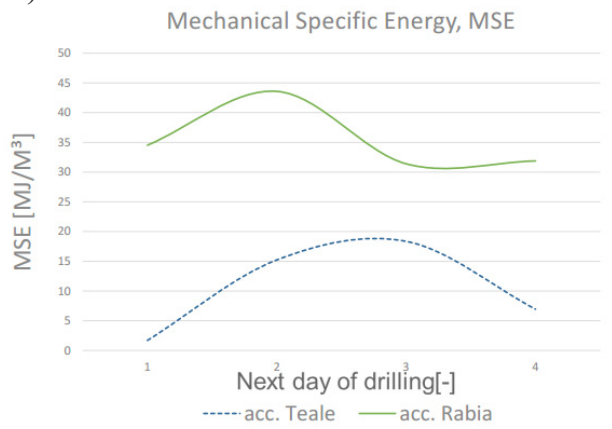

Fig. 2. MSE for: a) $81 \frac{1}{2}$ " PDC \#1 and PDC \#2 drill bits, IADC 343 - increase after the bit was exchanged; b) 8 1 $12^{\prime \prime}$ PDC \#1 and PDC \#2 drill bits, IADC 343; c) 8 1/2" PDC \#2 drill bit, IADC 343;

d) PDC 12 1/4" drill bit IADC 323

\section{INFLUENCE OF HYDRAULIC POWER IN DRILL BIT NOZZLES ON SPECIFIC ENERGY}

One of the main factors limiting and simultaneously determining the value of the described SE are hydraulic parameters of the drilling mud. Before the mud circulating in the circuit reaches the bottom of the borehole, it comes across a series of obstacles. It flows 
through a high pressure pipeline, the gooseneck, top drive or kelly to the drill string set. In the final phase, it flows through orifices (nozzles) in the drill bit or the crown putting more pressure on the bottom of the borehole to increase the crushing of the rock mass. The flow of drilling mud is burdened with pressure loss. It needs to be underlined that the pressure at the bottom of the borehole will be different from the pumping pressure.

Depending on the type of mud pumps used (duplex, triplex), we can calculate the theoretical value of the flow $Q_{r}(4),(5)$. By inserting the calculated value into equation (6), the demand for hydraulic power required in the drilling process is received.

Having accounted for the volumetric flow rate in particular types of pumps:

$$
\begin{aligned}
& \text { - duplex: } Q_{t}=3.143 \cdot \eta \cdot L \cdot\left(D^{2}-\frac{d_{t r}{ }^{2}}{2}\right)\left[\mathrm{m}^{3} / \mathrm{s}\right] \\
& \text { - triplex: } Q_{t}=2.356 \cdot \eta \cdot L \cdot D_{t}^{2}\left[\mathrm{~m}^{3} / \mathrm{s}\right]
\end{aligned}
$$

where:

$$
\begin{aligned}
\eta & - \text { mud pumps strokes }\left[\mathrm{s}^{-1}\right], \\
L & - \text { length of stroke }[\mathrm{m}], \\
D_{t} & - \text { mud pump liner diameter }[\mathrm{m}], \\
d_{t r} & - \text { mud pump rod diameter }[\mathrm{m}],
\end{aligned}
$$

we receive the amount of hydraulic power necessary for conducting the drilling, according to the equation:

$$
N_{h}=\frac{Q_{t} \cdot p}{60000}[\mathrm{~kW}]
$$

where:

$$
\begin{aligned}
N_{h} & - \text { hydraulic power needed on drilling process }[\mathrm{kW}], \\
p & - \text { discharge pressure }[\mathrm{kPa}], \\
Q_{t} & - \text { flow rate }\left[\mathrm{m}^{3} / \mathrm{s}\right] .
\end{aligned}
$$

Pressure losses occurring while overcoming flow resistance in the nozzles is calculated with equation (7).

$$
P_{d}=\frac{\gamma \cdot Q^{2}}{2959.41 \cdot C^{2} \cdot A^{2}}
$$

where:

$$
\begin{aligned}
P_{d}- & \text { pressure losses in nozzles }[\mathrm{MPa}], \\
\gamma & - \text { weight of mud }\left[\mathrm{kg} / \mathrm{m}^{3}\right], \\
Q- & \text { flow rate }\left[\mathrm{m}^{3} / \mathrm{s}\right], \\
A- & \text { cross-section area of the nozzles }\left[\mathrm{m}^{2}\right], \\
C- & \text { orifice coefficient }[-]: \\
& C=0.80-\text { bits without nozzles, } \\
& C=0.95-\text { bits with nozzles. }
\end{aligned}
$$


The Figures 3 and 4 present the dependence between pressure losses and mechanical specific energy calculated according to $\mathrm{H}$. Rabia and R. Teale equations respectively.

a)

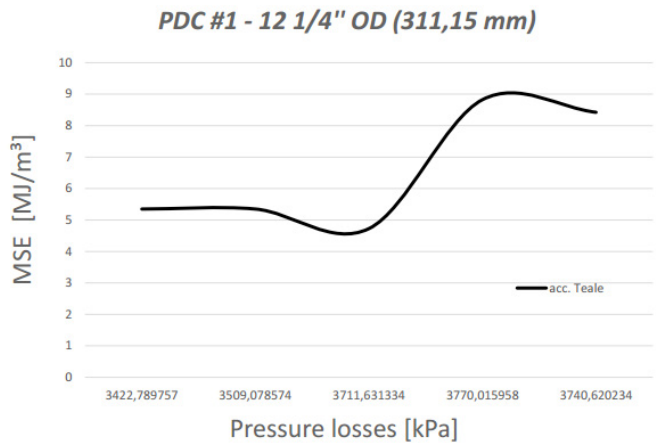

b)

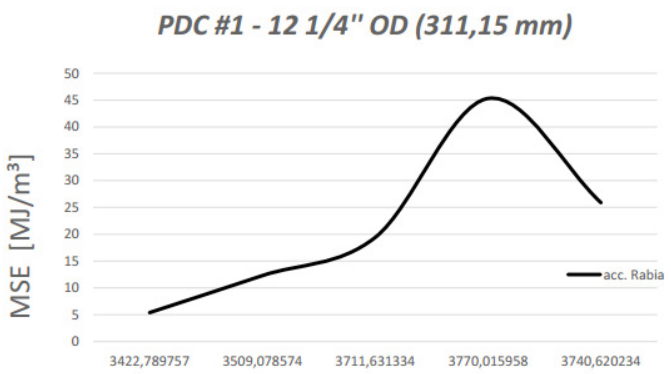

Pressure losses $[\mathrm{kPa}]$

Fig. 3. Dependence between MSE and pressure loss according to:

a) R. Teale equation; b) H. Rabia equation

PDC TX 6078 1/2" OD (311,15 mm)

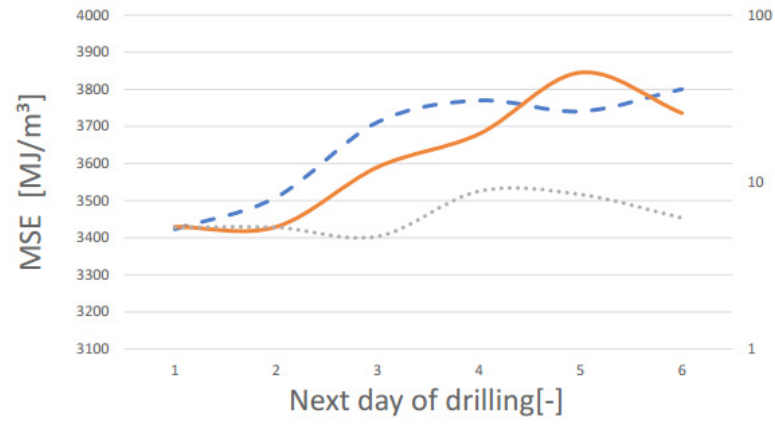

- - Pressure losses —acc. Rabia …... acc. Teale

Fig. 4. Comparison of pressure loss and MSE curves, calculated with R. Teale and H. Rabia equations 


\section{NEW SPECIFIC ENERGY INDEX - TOTAL SPECIFIC ENERGY}

Mechanical specific energy depends, first and foremost, on the hydraulic power utilized at the bottom of the borehole.

Thus, a new index for determining specific energy is proposed. Total Specific Energy (TSE) will account for not only mechanical effects but also the hydraulic power in drill bit nozzles.

The new TSE index will be based on the sum of below components.

Mechanical energy of linear motion of the drilling tool:

$$
\begin{gathered}
N=\frac{d W}{d t} \\
Z: W=\int F \cdot d s
\end{gathered}
$$

By comparing (8) and (9), we receive:

$$
N_{t}=\frac{F \cdot d s}{d t}
$$

If:

$Z: F=$ const.

$$
Z: \frac{d s}{d t}=v
$$

we receive:

$$
N_{l}=F \cdot v
$$

\section{Mechanical energy of rotary motion of the drilling tool}

Taking into consideration equations (8) and (9), and assuming that:

$$
M=F \cdot r \rightarrow F=\frac{M}{r}
$$

we receive:

$$
\begin{aligned}
W & =\int \frac{M}{r} d s \\
W & =\int M \cdot \frac{d s}{r} \\
W & =\int M \cdot d \varphi
\end{aligned}
$$

Having inserted (16) into (8), we receive:

$$
\begin{aligned}
& N_{0}=\frac{M d \varphi}{d t} \\
& N_{0}=M \cdot \omega
\end{aligned}
$$


We have to account for:

$$
\omega=2 \pi n
$$

so ultimately:

$$
N_{0}=M \cdot 2 \pi n
$$

\section{Hydraulic energy in the drilling tool}

$$
N_{h}=P_{d} \cdot Q
$$

Assuming that the flow is not subject to friction but is set and adiabatic, we may write down the energy balance equation for the fluid flowing through the nozzles at a given moment:

$$
\frac{p_{1}}{\rho \cdot g}+\frac{V_{1}^{2}}{2 g}=\frac{p_{2}}{\rho \cdot g}+\frac{V_{2}^{2}}{2 g}
$$

assuming that:

$$
V=\frac{Q}{A}
$$

and accounting for:

$$
\begin{gathered}
\frac{p_{1}-p_{2}}{\rho \cdot g}=\frac{V_{2}^{2}-V_{1}^{2}}{2 g} \\
\frac{\Delta p}{\rho \cdot g}=\frac{V_{2}^{2}-V_{1}^{2}}{2 g}
\end{gathered}
$$

by transforming equation (25) and after applying the simplification (26):

$$
V_{2}^{2}-V_{1}^{2} \cong V_{2}^{2}
$$

we can write down:

$$
P_{d}=\frac{\gamma \cdot Q_{t}^{2}}{2 g C^{2} \cdot A^{2}}=\frac{\rho \cdot Q_{t}^{2}}{2 C^{2} A^{2}}
$$

where:

$$
\begin{aligned}
p_{1} & - \text { liquid pressure in section A-A nozzle }[\mathrm{Pa}] \\
p_{2} & - \text { liquid pressure in section B-B nozzle }[\mathrm{Pa}] \\
V_{1} & - \text { liquid flow velocity in section A-A nozzle }[\mathrm{m} / \mathrm{s}] \\
V_{2} & - \text { liquid flow velocity in section B-B nozzle }[\mathrm{m} / \mathrm{s}] \\
\rho & - \text { density of liquids flows through the nozzles }\left[\mathrm{kg} / \mathrm{m}^{3}\right] \\
g & - \text { acceleration of gravity }\left[\mathrm{m} / \mathrm{s}^{2}\right] \\
\gamma & - \text { weight of liquid flows through the nozzles }\left[\mathrm{kg} / \mathrm{m}^{3}\right] \\
Q_{t} & - \text { flow rate }\left[\mathrm{m}^{3} / \mathrm{s}\right] \\
A & - \text { cross-sectional area }\left[\mathrm{m}^{2}\right] \\
C & - \text { orifice coefficient }[-] \\
P_{d} & - \text { pressure losses in the nozzle }[\mathrm{Pa}]
\end{aligned}
$$


If in equation (27) we assume the orifice coefficient to be $C^{2}=0.9025$ for drill bits with nozzles, and the cross-sectional area of the nozzle to be $A^{2}=0.61685$, then we obtain dependence (28) for losses in a single nozzle.

$$
P_{d}=0.8975 \cdot \frac{\rho \cdot Q^{2}}{d^{4}}
$$

Having taken into account the equivalent diameter of nozzles in the drilling tool, we receive the dependence (29), describing pressure loss in the drill bit.

$$
P_{d}=0.8975 \cdot \frac{\rho \cdot Q^{2}}{d_{e}^{4}}
$$

where $d_{e}$ - equivalent diameter of nozzles [m].

Because hydraulic power at the bottom of a borehole is the power of the mud pump (30) minus the value of pressure loss (31) inside the drill string and pressure loss in nozzles of the drilling tool (29), we have to take into account not only pressure loss occurring in the nozzles.

According to the statement above, we receive:

$$
\begin{gathered}
N_{p}=Q_{t} \cdot P_{p} \\
N_{w p r}=Q_{t} \cdot P_{w p r}
\end{gathered}
$$

where:

$N_{p}-$ power of the mud pump [kW],

$Q_{t}-$ volumetric flow rate of the mud pumped into the drill string $\left[\mathrm{m}^{3} / \mathrm{s}\right]$,

$P_{p} \quad-$ pressure of the mud pump $[\mathrm{Pa}]$,

$N_{w p r}^{p}-$ power spent on overcoming flow resistance inside the drill string [kW],

$P_{w p r}-$ pressure loss in the drill string $[\mathrm{Pa}]$.

Pressure loss $P_{w p r}$ inside the drill string in the case of a turbulent flow is calculated with the formula:

$$
P_{w p r}=\frac{32 \cdot f \cdot L \cdot Q_{t}^{2} \cdot \rho}{\pi^{2} \cdot D_{w}^{5}}
$$

where $f$-non-dimensional Fanning friction factor for a turbulent flow.

$$
f=\frac{0.047}{\operatorname{Re}^{0.21}}, \quad \operatorname{Re} \in\left(10^{4} \div 3 \cdot 10^{5}\right)
$$

where Re - Reynolds number [-]. 
Having considered the value of the friction factor from equation (33) in equation (32) we receive:

$$
P_{w p r}=\sum_{i=1}^{n} 0.145 \cdot \frac{\mu^{0.21} \cdot L_{i} \cdot \rho^{0.79} \cdot Q_{t}^{2.79}}{D_{i}^{4.79}}
$$

The sum of pressure losses in a circulating mud system, except for the drill bit, can be written as

$$
P_{w p r}=K_{w p r} \cdot Q_{t}^{m}
$$

where:

$K_{w p r}$ - coefficient dependent on the construction of the borehole and the drill string $[-]$,

$m$ - exponent accounting for the influence of the volumetric flow rate of drilling mud on flow resistance values in the mud circulating system (1.1-2.0).

$$
K_{w p r}=0.145 \mu^{0.21} \rho^{0.79}\left[\sum_{i=1}^{n} \frac{L_{i}}{D_{i}^{4.79}}\right]
$$

where:

$\mu-$ dynamic viscosity of the fluid inside the string [Pa $\cdot \mathrm{s}]$,

$L_{i}$ - length of the drill string [m],

$\rho-$ density of the fluid $\left[\mathrm{kg} / \mathrm{m}^{3}\right]$,

$D_{i}-$ diameter of the drill string [m],

by inserting dependencies (36), into equation (35), we receive:

$$
P_{w p r}=0.145 \mu^{0.21} \rho^{0.79}\left[\sum_{i=1}^{n} \frac{L_{i}}{D_{i}^{4.79}}\right] \cdot Q_{t}^{m}
$$

Ultimately, we can write down:

$$
N_{w p r}=0.145 \mu^{0.21} \rho^{0.79}\left[\sum_{i=1}^{n} \frac{L_{i}}{D_{i}^{4.79}}\right] \cdot Q_{t}^{m+1}
$$

and by using a simplification in compliance with equation (36), we receive:

$$
N_{w p r}=K_{w p r} \cdot Q_{t}^{m+1}
$$

The hydraulic power delivered to the bottom of the borehole according to transformations presented above is written as:

$$
N_{h}=N_{p}-N_{w p r}-P_{d}
$$

The total power takes the form:

$$
\Sigma N=N_{l}+N_{o}+N_{h}
$$


The real measure of energy efficiency of drilling rocks should be the value which we propose to name Total Specific Energy (TSE). We propose that the value should be defined as the index of quotient of the total energy used on drilling to the volume of drilled mass.

Having determined single elements of energy influencing the value of TSE according to the new index, we can write down:

$$
T S E=\frac{\sum N}{V}
$$

To account for values in a certain amount of time, we formulate:

$$
T S E=\frac{N_{l} \cdot \Delta t+N_{o} \cdot \Delta t+N_{h} \cdot \Delta t}{A \cdot H}
$$

If the cuttings drilled with the drill bit $H$ in equation (43) are written down as:

$$
H=v \cdot d t
$$

then:

$$
T S E=\frac{N_{l} \cdot \Delta t+N_{0} \cdot \Delta t+N_{h} \cdot \Delta t}{A \cdot v \cdot d t}
$$

Having inserted equations (12), (20) and (40) into formula (45) and having accounted for $A=\frac{\pi d^{2}}{4}$, we receive:

$$
T S E=\frac{4 F \cdot v+8 \pi \cdot n \cdot M+4\left[Q_{t} \cdot P_{p}-K_{w p r} \cdot Q_{t}^{m+1}-3.59 \frac{\rho \cdot Q_{t}^{3}}{d_{e}^{4}}\right]}{\pi \cdot d^{2} \cdot v}
$$

where:

$$
\begin{aligned}
\text { TSE } & - \text { total specific energy }\left[\mathrm{MJ} \cdot \mathrm{m}^{-3}\right], \\
F & - \text { axial pressure on the drill bit }[\mathrm{N}], \\
v & - \text { rate of penetration, } \mathrm{ROP}[\mathrm{m} / \mathrm{s}], \\
n & - \text { drill bit rotation }\left[\mathrm{s}^{-1}\right], \\
M & - \text { torque }[\mathrm{Nm}], \\
d & - \text { borehole diameter }[\mathrm{m}] .
\end{aligned}
$$

In accordance with the applied calculations, a comparison was made between the curve of drilling energy drawn according to the proposed methodology and curves resulting from the R. Teale and H. Rabia equations. The method takes into account the hydraulic energy used at the bottom of the borehole. 


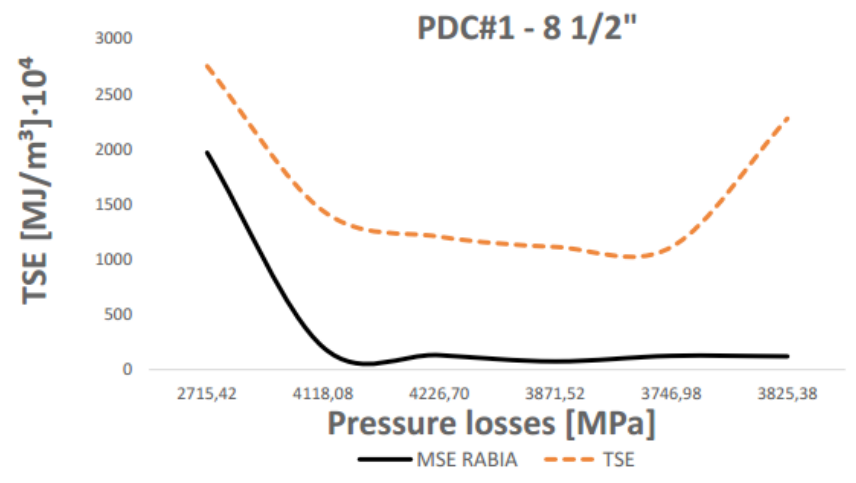

Fig. 5. Comparison between MSE (H. Rabia) and TSE curves in reference to pressure losses

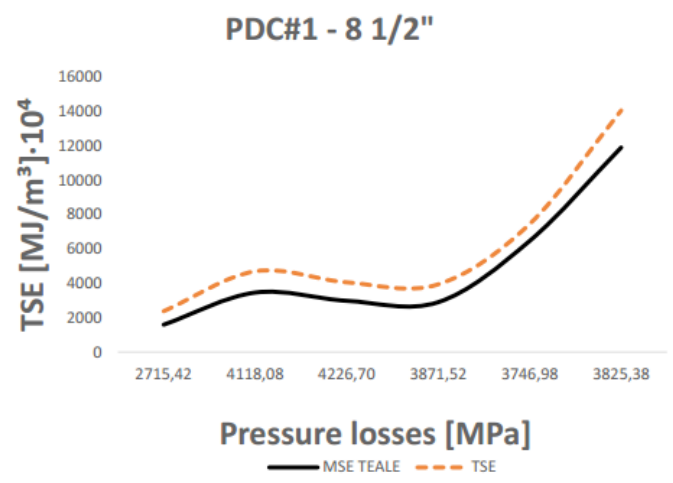

Fig. 6. Comparison between MSE (R. Teale) and TSE curves in reference to pressure losses

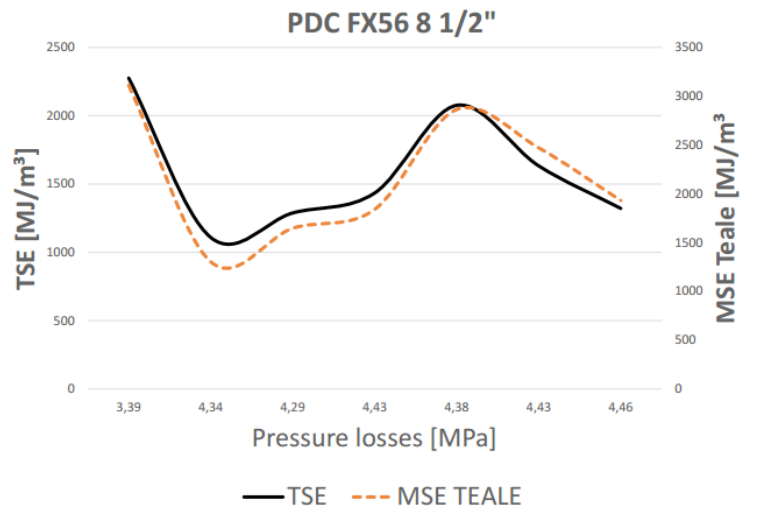

Fig. 7. Comparison between MSE (R. Teale) and TSE curves in reference to pressure losses 


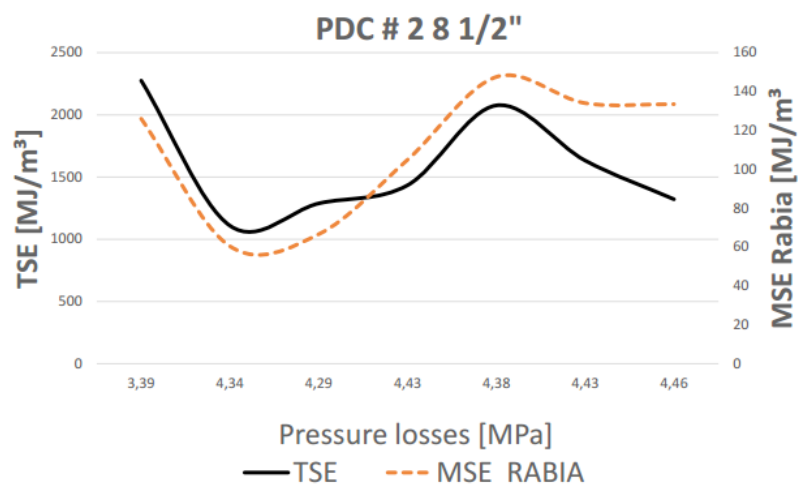

Fig. 8. Comparison between MSE (H. Rabia) and TSE curves in reference to pressure losses

\section{CONCLUSIONS}

In order to adequately select a drill bit, numerous data needs to be collected. Depending on the method of the selection of a drill bit, as well as on the way of elimination of certain data, the required data can be narrowed down. The drilling parameters data base that is required for the proper selection of the drill bit is influenced, first and foremost, by the method of selection. Literature of the field presents many ways of selection. It is hard to establish which of them are more efficient and, thus, give better results. A noticeable growth of MSE visible in Figure 2a is not a natural MSE curve, but only depicts increase in MSE after exchange of the drill bit. The replacement occurred because of a drop in the mechanical drilling rate. However, it needs to be underlined that the exchange resulted in an increase in MSE, despite the fact that the drilled layers were similar in lithostratigraphy (the Upper and Medium Silurian). We may conclude that the increase occurred because of the insertion of a previously used drilling tool. Lowering a new drill bit would be depicted in a graph with a decreasing MSE. In this case, the type of the drill bit does not influence the curve, since both of them were described with IADC 343. Moreover, according to Figure 2a, it should be stated that the MSE equation proposed by H. Rabia perfectly reflects the trend of the MSE equation presented by R. Teale in 1965, even though it does not account for the torque of the drilling tool. Proper selection of the drill bit helps in achieving good economic results. It is one of the paramount indexes in exploration and accessing hydrocarbon reservoirs. By comparing the curves of MSE (Fig. 2c), we can clearly state that curves reflecting both the $\mathrm{R}$. Teale and $\mathrm{H}$. Rabia equations are similar. There is a similar behavior of MSE with the use of PDC IADC 343 drill bit during drilling. It supports the view that $\mathrm{H}$. Rabia made engineering calculations of MSE easier and by elimination and transformation of the equation, now not including torque. The selection of the drill bit was properly selected for the drilled rock formations. It is proven by a slump after the first 24 hours and successive drop.

Figure $2 \mathrm{~b}$ shows the difference between MSE curves of used drill bits. The MSE of drill bit no. 1, calculated with R. Teale equation, after the exchange of the bit rises. It seems, based on the data from previous drilling works, that the bit was selected inadequately, which was used as second in the deepening of the borehole. An important aspect in the process of drill bit selection was 
also data, which was generated by the drill bit pulled out of the borehole. On the other hand, the curve of MSE calculated with the use of $\mathrm{H}$. Rabia equation shows an increase in the drilling power of the second curve, after the exchange of the drill bit. It proves the point that curves of MSE calculated with R. Teale and H. Rabia equations, despite different data required, show similar trends.

As MSE grows, we observe pressure loss in nozzles of the described PDC bit. It results from the increase in axial thrust and bit rotation, which increases the drilling rate. The result of increased drilling rate is an increased amount of cuttings and rock fragments on the bottom of the borehole, which have to be removed so as to ensure proper drilling rate. A clean bottom of a borehole ensures nearly maximum area of contact between the drilling tool and the drilled rock mass. Cleaning the bottom of a borehole is achieved through properly selected parameters of the drilling fluid and higher pumping pressure. Increased pressure results in increased pressure loss in drill bit nozzles. It is clearly visible in the charts showing the dependence between pressure loss in drill bit nozzles and MSE. By eliminating the need to include torque in equation (3), it is easier to calculate and evaluate the described TSE in a more precise way.

The proposed methodology of calculating the new index includes hydraulic power used in drilling at the bottom of a borehole. Pressure loss for overcoming flow resistance in the lower part of the drill string amount to even $60 \%$ of the total loss during drilling. Hence, it is paramount to select an adequate drilling tool, which will generate less pressure loss. Taking into account hydraulic power in the proposed index gives the opportunity to analyze the drill bits applied. Knowledge of parameters of drilling tools used in boreholes developed earlier in a given area enables proper and optimal selection of drilling tools for given conditions. Curves which include hydraulic power (Fig. 5-8) were drawn based on equation (46). The visible difference between TSE and MSE is caused by the inclusion of hydraulic power. As presented in figures, the curves drawn based on the proposed TSE index show trends similar to those based on the R. Teale and H. Rabia equations. It shows that the methodology of including hydraulic power expended at the bottom of a borehole is sound in the case of selection of drilling tools. Pressure losses at the bottom of a borehole comprise the majority of all losses expended for overcoming flow resistance of the drilling fluid in drill string elements and the annulus. Hence, hydraulic power should be considered in particular. The proposed index reflects the behavior of the drilling fluid during its flow, which was neglected in the R. Teale and H. Rabia equations.

\section{REFERENCES}

[1] Macini P., Magagni M., Valente P.: Drill bit catalog and bit-index: New method for bit performance evaluation. Latin American and Caribbean Petroleum Engineering Conference, Rio de Janeiro, 20-23 June 2005, SPE 94798.

[2] Masson F.K.: Three-cone bits selection with sonic logs. SPE Annual Technical Conference and Exhibition, Houston 16-19 September 1984, SPE 13256.

[3] Rabia H., Farrelly M., Barr M.V.: A new approach to drill bit selection. SPE European Petroleum Conference, London 20-22, October 1986, SPE 15894.

[4] Vargo L.: On the optimal time to pull bit under conditions of uncertainty. JPT, December 1982.

[5] Wiśniowski R., Toczek P.: The methods of pore pressures prediction based on seismic well logs. AGH Drilling, Oil, Gas, vol. 32, no. 3, 2015, pp. 551-563. 
